\title{
A Content Analysis of Change Management Strategies Used in Technological Transitions in Higher Education Institutions from the Lens of a Strategic Alignment Framework
}

\author{
Ingrid Guerra-López \\ Wayne State University \\ Siba El Dallal \\ University of Michigan
}

\begin{abstract}
Technology innovations have the potential to significantly strengthen the ability of higher education institutions to deliver on their core educational mission with greater quality, efficiency, and effectiveness. Not surprisingly, managing technological changes is among the chief concerns for institutional leaders, and yet there is a dearth of research that provides concrete frameworks for managing this type of change in a higher education context. Using Guerra-López and Hicks's Learning and Development Strategic Alignment (LDSA) framework, this qualitative study used a directed content analysis approach to develop a contextualized framework for planning and managing technology change in higher education institutions. The findings suggest that there is a meaningful fit between specific change management strategies found in the learning management systems (LMS) transition research literature and the LDSA framework. The various strategies were synthesized and grouped around LDSA dimensions and core functions, resulting in a technological change management framework contextualized for higher education.
\end{abstract}

Keywords: Strategic Alignment, Change Management, Higher Education, Institutional Effectiveness, Learning Management System (LMS) Selection, LMS implementation, LMS transition/migration.

Guerra-López, I., \& Dallal, S. (2021). A content analysis of change management strategies used in technological transitions in higher education institutions from the lens of a strategic alignment framework. Online Learning, 25(3), 191-207. doi:10.24059/olj.v25i3.2395 
One of the aims of higher education institutions (HEI) is meeting the evolving needs of students, the labor market, its community, and society at large. Leveraging pedagogical developments and technological innovations can significantly strengthen higher education's ability to deliver on this promise. The challenge in fully realizing the benefits of technology innovations is wide recognition that technology is a means to an end and that purposefully aligning these innovations to strategic imperatives is the foundation for successfully managing technological change.

Implementing planned organizational change is one of the most significant challenges for leaders and those responsible for the organization's improvement and sustainability (GuerraLópez \& Hicks, 2017; Mishra, 2018), and in HEI managing technological changes is a key concern (Ryan et al., 2012, p. 222). In addition, Dobbin (2016) asserted that change management might be the most complicated issue to address, given the "resistance-to-change" problem when upgrading to a new technology that is common in any organization and even more evident in Higher Education. Adopting a technology, such as a new LMS, is a complex process (Straub, 2009; Englund et al., 2017) as it involves a change in the delivery approaches and content that may affect various aspects of the educational system. Moreover, failure to define clear stakeholder expectations and establish tangible alignment between the selected solutions and the institution's strategic priorities increases the risk for wasted efforts, time, and money that can lead to poor performance in the organization (Guerra-López \& Hicks, 2017).

The literature consistently estimates the failure rates of organizational change initiatives to be as high as 70\% (Hornstein, 2015; Al-Haddad \& Kotnour, 2015; Balogun \& Hailey, 2004). Technology changes in HEIs have not always been implemented with systematic consideration of the needs of a wide variety of stakeholders, including students and faculty, thereby creating a gap between the perceived gains of educational technology and tangible student outcomes (Adams Becker et al., 2017). Challenges that accompany the implementation of technological changes include high cost, insufficient resources, faculty disinclination to change, inadequate involvement of technology staff (Glenn \& D'Agostino, 2008), in addition to the pressure of planning to grapple with technological obsolescence and longevity (Adams Becker et al., 2017). Just about the time faculty can adapt and master a technology, a new version is launched and marked, demanding a new cycle of implementation and adoption. For example, introduction of a new learning management system (LMS) is a significant institution-wide change that requires well-planned strategies and a sound decision-making process. Moreover, it requires involving a wide range of key stakeholders in the adoption process phases, including planning, selection, implementation, and evaluation (Boggs \& Van Baalen-Wood, 2018). These technologies will be ineffective or distracting if they are not managed and integrated into the learning process in meaningful ways (Adams Becker et al., 2018)

Many studies have discussed the challenges that HEI face when changing their LMSs. These include short transition time and lack of faculty involvement (Hannon et al., 2011), resistance to change, time demands for faculty training and associated compensation (Ryan et al., 2012), extra workload from course re-design and the possibility of re-training (Smart \& Meyer, 2005), besides other issues that might hinder faculty teaching and impact student learning.

Clearly, the use of effective strategies to successfully manage technological change in HEI is crucial. Nevertheless, managing technological change in higher education has not been adequately studied. Much of the research and practice has been borrowed from the corporate world and contextualized change management practices for higher education do not exist (DePaul, 2016). Despite the vast amount of research on e-learning technologies, the focus has 
been on teaching and learning with technology. Consistently, Ritzhaupt and Thompson (2017) argue that there is only a modest amount of extant research literature on the planned processes involved in selecting an LMS. Other scholars have contended that change management models or frameworks that ensure successful e-learning implementation in addition to identifying critical success factors in teaching, learning, and management are needed to help academic leaders facilitate the change process (McPherson \& Nunes, 2006; Pahl, 2003; Wilson, 1999). A review of the literature reveals publications on the LMS transition process and lessons learned from the implementation. Yet, there is a dearth of published efforts to help institutional leaders in higher education understand the process from the lens of an integrative theoretical framework that can systematically guide them in aligning the change initiative to the institution's objectives.

Therefore, the purpose of this qualitative study is to explore the empirical literature and identify what strategies are being used in higher education to facilitate the selection and implementation of an LMS migration from the lens of a theoretical framework for strategically planning and managing institutional change.

\section{Theoretical Framework}

In his classic book, Organizational Culture and Leadership (1985), the well-known scholar, Edgar Schein, defined culture as a pattern of shared basic assumptions learned by a group of people as it solves the problems of external adaptation and internal integration. (p.18) Schein and Schein (2016) argued that this internal integration depends on obtaining a shared understanding of the organization's mission and strategy, its goals and objectives, the means it will employ to reach them; the measurement system it will use to navigate its path, and the corrections or improvement strategies it will take to stay the course. This is the fundamental premise underlying the definition of strategic alignment as a process of continuous adaptation to create a fit among the internal and external elements of an organization and its strategic priorities (Guerra-Lopez, 2018). Previous research had suggested that strategic alignment is vital to performance and that organizations with strong strategic alignment outperform those with weak alignment (Guerra-Lopez \& Hicks, 2017; Hicks, 2015; Jin et al., 2010; Marsick \& Watkins, 2003; Walter et al., 2013). Linking the activities in the organizations in a way that adds measurable value to all the internal and external stakeholders is the key to achieving success. The lack of alignment emphasis creates the risk of wasted time, efforts, and money and can lead to poor performance and demotivation among its members.

The Strategic alignment of Learning and Development framework (Figure 1) is a change management tool that can be used to clarify stakeholder expectations and validate organizational needs to ensure the best initiatives are selected and effectively implemented in any type of organizational setting. Change management models often involve three key stages for managing the implementation of organizational initiatives: communicating the change, mobilizing others to support the change, and monitoring the implementation of change. In the context of strategic alignment, the change process begins prior to communicating the change and begins with an assessment and validation of the problems to be addressed. In this sense, specific change initiatives are driven by well-defined needs and requirements. The framework is grounded on systems theory to investigate how organizational elements, factors, and dynamics work together to produce a specific result. It also relies heavily on cross-collaboration and strategic thinking to inform decision-making and direction setting (Guerra-Lopez \& Hicks, 2015; 2017).

The strategic alignment framework was developed to help decision-makers understand the relationships among essential factors that impact organizational success, whether they are 
internal elements such as systems, staff, skills, structure, finance, and shared values and practices, or external elements such as, government laws, environmental policies, customer needs, technology trends, economic environment, regulatory agencies, or peers or competitors.

Figure 1.

Strategic Alignment of Learning and Development model, (source: Strategic Alignment for Learning and Development by Guerra-Lopez \& Hicks, 2017, p.26)
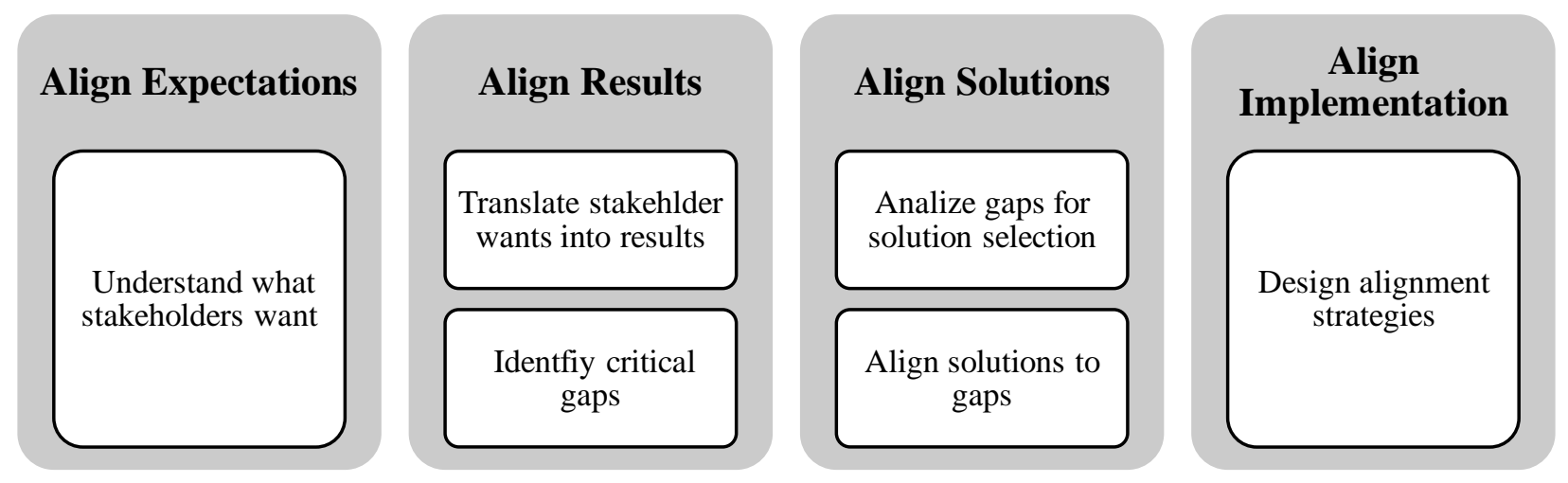

Guerra-Lopez and Hicks (2017) suggested that most failed implementations of organizational initiatives stem from either the misalignment of the perceived problem and the selected solution or the misalignment of the selected solution and the implementation context. In the former, the disconnect is in properly assessing the needs of the organization and selecting the best solution(s) for addressing those needs. In the latter, the disconnect stems from poor or non-existing strategies for purposefully implementing the solution and managing the change.

\section{Methodology}

This qualitative study took a directed approach to content analysis (Hsieh \& Shannon, 2005) using the Strategic Alignment of Learning and Development (LDSA) framework to derive the primary coding categories for the analysis of text data.

This study focused on one specific type of technological change, learning management system (LMS) transitions. Piña (2018) defined an LMS as "a software system that interfaces with one or more databases and provides a secure environment to facilitate delivery, interaction, assessment, and management of online, hybrid, and web-enhanced instruction via the Internet" (p. 102). According to the 2014 EDUCAUSE Center for Analysis and Research (ECAR) report, LMS adoption reaches an extraordinary level of HEIs with more than $99 \%$ of colleges and universities reporting that they have an LMS in place and that these tend to stay in place for only eight years before institutions look to update them (Dahlstrom et al., 2014).

Thus, the researchers conducted a comprehensive bibliographic search using key terms such as "Learning Management System Selection”, "Learning Management System Implementation", "Learning Management System Transition”, "LMS selection”, "LMS Implementation", "LMS Transition" between the period of January 1, 2012-July 17, 2019. The search efforts yielded 135 publications, including 130 journal articles, three book chapters, and two books from the Wayne State University library system. 
The researchers then used additional criteria to identify the most relevant publications, which included full-text online English case study articles describing specific strategies utilized by HEIs during the LMS transition process. A snowball sampling technique was then used to identify additional empirical publications from the reference lists that also met the criteria. Two additional articles were added to the sample for a total of $11 \mathrm{LMS}$ transition case studies.

Content analysis of themes was followed in which coding was used to determine the emerging themes and patterns from the studies. Change management strategies were grouped around naturally emerging themes. Based on a reiterative process of the organization, reflection and discussion, the researchers found that there was considerable fit between the emerging themes and the strategic alignment framework (though not all themes appeared in all case studies) at which times the specific strategies were organized around theoretical framework dimensions, stages, and steps, as illustrated in Table 1.

\section{Findings}

Below we provide a description of the contextualized strategic alignment framework based on the content analysis. The findings are presented under each of the main four phases: Align Expectations, Align Results, Align Solutions, and Align Implementation. The presentation of each phase begins with the theoretical description and is followed by the research findings.

\section{Phase 1. Align Expectations}

This phase helps higher education information technology (IT) leaders gain an understanding of the expectations, wants, and perceived performance needs from various stakeholder perspectives of the HEI. Here, the stakeholders include all those who are involved in the technological change, in this case the LMS transition, including those championing the transition as well as those who will be affected by the LMS transition, including faculty, students, staff, executive and academic leadership, center for teaching and learning (or some comparable unit), and other relevant unit representatives.

Gaining an understanding of the stakeholders' perspectives has many important functions, including helping change leaders understand how success will be evaluated across the institution, as well as what elements can help them establish strong buy-in for the process, the solution, and the ultimate results (Guerra-Lopez, 2017). In a sense, this is the beginning of creating and managing the organizational change - as people become engaged in the process, they have a shared interest in the change process and its success. It also helps build a shared understanding of the problems from various vantage points and a clearer understanding of how the various issues interact as part of one institutional system embedded within a community or societal context. The content analysis revealed the following specific strategies for this phase:

1. Engaging Stakeholders: Studies emphasized involving stakeholders early in the process to gain faculty buy-in later. Representatives of all stakeholders including, students, faculty, administrators, IT staff are all invited to the conversion (Boggs, \& Van BaalenWood, 2018; Graff, Johnson, \& Means, 2013).

2. Identify Drivers of Stakeholder's Needs and Uncover Their Expectations: Obtaining information about students and faculty LMS usage, needs, and impressions about the current LMS as well as their desires and expectations for a new system help the change agents make a sound decision around LMS selection. This can be done through online surveys, focus groups - online or face-to-face (Boggs, \& Van Baalen-Wood, 2018; Graff, Johnson, \& Means, 2013; Strawser et al., 2018), and User Story (Koutropoulos, 
2013) that can be used to create an inventory of needs and to evaluate potential LMS.

Koutropoulos, (2013) explained that:

a user story is a brief description, in the form of a sentence that describes what the user of a software system wants to achieve by using this system. User stories are written by users of the system, not developers, and they are meant to express the voice of the user. By using user stories for collecting requirements and evaluating the creators of the LPR process wanted to ensure that the interests of all of the campuses were preserved. (p.24).

3. Identify Change Agents: They can be members of the main departments at the institution that are chosen to form a review committee. Graff, Johnson, and Means (2013) explained,

The selection of participants for the committee sought to achieve two goals: instructor leadership and direction of the evaluation and selection process (rather than by IT staff), and campus-wide participation (p. 56).

\section{Phase 2. Align Results}

Stakeholder wants and expectations are not always neatly articulated in terms of specific institutional objectives, and the transition team can be instrumental in clarifying links between the two. The aim of this phase is to clarify the specific results that will be achieved with the chosen initiative. These results cross over various dimensions, such as effective teaching, the learning experience, student success and institutional effectiveness among others. Clarifying expected results sheds light on relevant indicators and the data needed to document clear gaps between desired and current results. A variety of methods can be used to clarify gaps, including review of relevant institutional data, focus groups, and interviews. Perhaps not all gaps are of equal importance or share the same level of urgency; therefore, having a systematic process for identifying priorities allows the transition team to clarify the problems to be addressed, and helps focus further analysis, selection, and implementation.

For this phase, two strategies emerged from the studies:

1. Identify Needs or Gaps: Graff, Johnson, and Means (2013) explain that the review committee align the selection process with the institution plan and its objectives, specifically, with e-Learning system and services.

2. Conduct Institutional (resources) Analysis: Analyze the culture, strategic plan, and the context of the organization to determine where the LMS fits and operates (Boggs, \& Van Baalen-Wood, 2018) in addition to the availability of resources and budget (Strawser et al., 2018).

\section{Phase 3. Align Solutions}

The goals of the analysis at this stage according the LDSA framework are to clarify the root causes of problems associated with the current LMS and begin to articulate the "solution requirements", which in turn provide an evidence basis for identifying LMS alternatives that will have the highest likelihood of success. It is also important to understand how other issues or dynamics in the environment may be supporting recurrent patterns that support undesired or counterproductive LMS routines. It is also essential that the process of identifying LMS alternatives be collaborative and include input from stakeholders, beginning with identifying relevant and useful criteria for selecting the options. This helps ensure that the selection process incorporates documented institutional needs, capabilities, resources, and preferences, as well as the track record of LMS options. The various solution requirements are weighed and prioritized by the stakeholders and used to evaluate each of the LMS alternatives. Six main strategies emerged from the literature within this phase: 
1. Participatory Solution Analysis: Information is collected about the problem and dissatisfaction components that drove the institution to upgrade the system and the gaps to be addressed. Strawser et al., (2018) found that the age, limitations, and the maintenance cost of the old LMS system created compelling reasons for the institutional shift.

2. Locating Experiences of Peer Institutions: Locating peer institution experiences that had recently gone through LMS transition is found to be helpful (Boggs, \& Van BaalenWood, 2018; Graff, et. al., 2013).

3. Request for Proposals (RFP): Developing RFP and locating the proposals that meet the institution's specific needs and context is necessary at this stage (Boggs, \& Van BaalenWood, 2018; Koutropoulos, 2013).

4. Vendor Presentations \& Review: Vendors are invited to present their products to faculty, students, administrators, and technical groups in on-site meetings (Graff et al., 2013; Koutropoulos, 2013; Davis \& Surajballi, 2014, Boggs, \& Van Baalen-Wood, 2018).

5. Technical Testing and Evaluation: After the presentation, the committee invites instructors and support staff to test the proposed systems (Graff et al., 2013; Davis \& Surajballi, 2014). Technical testing, evaluation scores, and feedback are then collected.

6. Decision/Solution Selection: Final decision about the best LMS is made based on previous testing. (Boggs \& Van Baalen-Wood, 2018; Graff et al., 2013). Boggs and Van Baalen-Wood (2018) recommend the rule of 80/20 and stated, "You won't be able to please everyone; aim for meeting the needs of $80 \%$ of your user base" (p.119).

\section{Phase 4. Align Implementation}

The focus of this last phase is ensuring successful execution, integration, and sustainability of the change. The implementation plan must include specific steps for integrating the new LMS in the actual environment, which includes a thoughtful communication strategy. The transition teams should consider who needs to be informed about what, when, and how as it is related to the transition. Implementation planning also includes mobilization strategies, such as defining implications for other systems, policies, processes and procedures, expectations, training, feedback, and evaluation. It may also include forming implementation support teams across various units to proactively address questions or help troubleshoot. Finally, a clear monitoring plan to track the progress and success of the LMS transition must be defined, which should include what milestones and indicators will be tracked, how frequently data will be collected, who should use it and when, and how to use the data for timely corrective or improvement actions. The content analysis revealed four strategies under this phase:

1. Development of Implementation, Monitoring, and Improvement Plan: Having an implementation plan and an implementation team is vital to put in strategies to aid the implementation process (Davis, \& Surajballi, 2014; Strawser et al., 2018).

2. Communication Strategies \& Informational Sessions: Developing and maintaining robust communication strategies (Boggs, \& Van Baalen-Wood, 2018; Butakov et al., 2013; Davis \& Surajballi, 2014; Graff et al., 2013; Hannon et al., 2011; Ryan et al., 2012; Koutropoulos, 2013, Strawser et al., 2018) is essential in keeping people informed and apprised of the next steps in the transition, training, and ongoing support. Multiple informational/introductory sessions can be provided across campus and online for faculty, students, and staff to support the LMS implementation (Killewo et al., 2014; Boggs \& Van Baalen-Wood, 2018; Strawser et al., 2018). Change brings about insecurity 
and uncertainty. Resistance to change is considered an obstacle in the change management and is linked to its failure. Most resistance and opposition to change result from fear, uncertainty, and negative perspective of the new technology. Communication helps to address the resistance and opposition to change and facilitate effective technological change (Guerra-Lopez \& Hicks, 2017; Ryan et al., 2012; Boggs \& Van Baalen-Wood, 2018).

3. Execution of Implementing Plan with the Necessary: (Boggs \& Van Baalen-Wood 2018; Butakov et al., 2013; Killewo et al., 2014; Judge \& Murray, 2017; Sanga, 2016; Hannon et al., 2011; Ryan et al., 2012; Strawser et al., 2018)

a. Training: Multifaceted training can be offered to users around content migration through workshops (basic and advanced skills workshop, foundational and targeted workshops), stand-alone sessions and series, digital training repository, and boot camp, custom workshops, sessions in users' home departments, and ondemand training. Strawser et al., (2018) argued, "faculty must understand what the LMS can do and how it can be used in the classroom" (p.40).

4. Support: Robust support from a support team that includes the vendor, IT, and instructional support personnel can be offered 24/7 through phone calls, email, online live chat, video guides, PDF guides, help page, one-on-one-appointments, or ongoing drop-in support services at individual to departmental levels.

a. Collaboration and Cooperation: Judge and Murray (2017) explained that "collaboration and cooperation of the trainers and the faculty were vital to the success of the project. Collaboration consisted of scheduled meetings, structured deadlines to upload documents, and assistance for faculty and staff with individual courses." (p. 278)

b. Resources and Leadership: Support and encouragement from leadership are crucial to empower stakeholders. Citing Ely (1990), Strawser et al. (2018) explained that "leadership refers to leaders who provide encouragement to consider ideas, ensure necessary training, communicate enthusiasm, and are available for consultation." (p. 42). Leadership of high quality is required to guide an effective change. Bates (2000) argued that without leadership and a strong sense of support for change in the organization, the barriers of inertia will be great.

c. Incentives, Rewards and Early Adopters: Studies refer to recruiting early adopters and mentors to pilot the system and guide the content migration process as they play a vital role in the technological change process (Ryan et. al., 2012; Boggs \& Van Baalen-Wood, 2018; Strawser et al., 2018). Strawser et al. (2018) recruited Moodle ambassadors to leverage the passion of first adopters and gave them incentives; they state, "The monetary incentive reminded faculty that their work was valuable." (p. 41)

d. Taking Learning Ownership: Encourage academics to take ownership of what they do is a key. Hannon, et. al., (2011) emphasized learning by doing, scaffolding professional development, adopting project approach, and providing a creative environment.

e. Integrating the New LMS in other Relevant Structures and Processes at the institution, such as with student information system. 
- Monitoring, Change Management \& Continuous Improvement Plan: At the completion of the transition, continual evaluation and feedback from faculty and students will be vital to determine the effectiveness of the project and to suggest plans for improvement (Judge \& Murray, 2017). This can be done through a variety of methods, including surveys (Judge \& Murray, 2017), or continuously via online suggestion boxes (Ryan, Toye, Charron \& Park, 2012). Table 1, below, summarizes the specific strategies found in the literature, as well the supporting references. 
Table 1.

A Synthesis of Technological Change Management Strategies Organized around the Four Strategic Alignment Framework Phases Strategies Source Description

\section{Align Expectations}

\begin{tabular}{|c|c|c|}
\hline $\begin{array}{l}\text { Engaging } \\
\text { Stakeholders }\end{array}$ & $\begin{array}{l}\text { Boggs \& Van Baalen- } \\
\text { Wood (2018); Graff et al. } \\
(2013)\end{array}$ & $\begin{array}{l}\text { Involving stakeholders early in the process to gain faculty buy-in later. Representatives } \\
\text { of all stakeholders including, students, faculty, administrators, and IT staff are all } \\
\text { invited to the conversion. }\end{array}$ \\
\hline $\begin{array}{l}\text { Identify Stakeholder } \\
\text { Expectations }\end{array}$ & $\begin{array}{l}\text { Boggs \& Van Baalen- } \\
\text { Wood (2018); Graff et al. } \\
(2013) \text {; Strawser et al. } \\
\text { (2018); Koutropoulos } \\
(2013)\end{array}$ & $\begin{array}{l}\text { Obtaining information about students and faculty LMS usage, needs and impressions } \\
\text { about the current LMS as well as their desires and expectations for a new system help } \\
\text { the review committee make a sound decision around LMS selection. } \\
\text { This can be done through: } \\
\text { - An online survey } \\
\text { - focus groups (online or face-to-face) } \\
\text { - User Story }\end{array}$ \\
\hline $\begin{array}{l}\text { Identify Change } \\
\text { Agents }\end{array}$ & $\begin{array}{l}\text { Graff, Johnson \& Means } \\
\text { (2013); Boggs \& Van } \\
\text { Baalen-Wood (2018) }\end{array}$ & $\begin{array}{l}\text { Members from the main departments at the institution are chosen to form a review } \\
\text { committee. }\end{array}$ \\
\hline \multicolumn{3}{|l|}{ Align Results } \\
\hline $\begin{array}{l}\text { Identify Needs or } \\
\text { Gaps }\end{array}$ & Graff et al. (2013) & $\begin{array}{l}\text { Graff, Johnson, \& Means (2013) explain that the review committee aligns the selection } \\
\text { process with the institution plan and its objectives, specifically with e-Learning system } \\
\text { and services. }\end{array}$ \\
\hline $\begin{array}{l}\text { Conduct Institutional } \\
\text { Analysis }\end{array}$ & $\begin{array}{l}\text { Boggs \& Van Baalen- } \\
\text { Wood (2018); Strawser et } \\
\text { al. (2018) }\end{array}$ & $\begin{array}{l}\text { Analyzing the culture, strategic plan, and the context of the organization to determine } \\
\text { where the LMS fits and operates. In addition to the availability of resources and } \\
\text { budget. }\end{array}$ \\
\hline \multicolumn{3}{|l|}{ Align Solutions } \\
\hline $\begin{array}{l}\text { Participatory Solution } \\
\text { Analysis }\end{array}$ & $\begin{array}{l}\text { Strawser et al. (2018); } \\
\text { Graff et al (2013) }\end{array}$ & $\begin{array}{l}\text { At this stage, information is collected about the components that drove the institution } \\
\text { to upgrade the system. Further, the selection process needs to be aligned with the } \\
\text { institution plan and its objectives. }\end{array}$ \\
\hline $\begin{array}{l}\text { Locate Experiences } \\
\text { of Peer Institutions }\end{array}$ & $\begin{array}{l}\text { Boggs \& Van Baalen- } \\
\text { Wood (2018); Graff et al. } \\
(2013)\end{array}$ & $\begin{array}{l}\text { Locating experiences of peer institutions that had recently gone through LMS } \\
\text { transition. }\end{array}$ \\
\hline
\end{tabular}




\begin{tabular}{|c|c|c|}
\hline $\begin{array}{l}\text { Request for Proposals } \\
\text { (RFP) }\end{array}$ & $\begin{array}{l}\text { Boggs \& Van Baalen- } \\
\text { Wood (2018); } \\
\text { Koutropoulos (2013) }\end{array}$ & $\begin{array}{l}\text { Developing RFP and locating the proposals that meet the institution's specific needs } \\
\text { and context. }\end{array}$ \\
\hline $\begin{array}{l}\text { Vendor Presentations } \\
\text { and Review }\end{array}$ & $\begin{array}{l}\text { Boggs \& Van Baalen- } \\
\text { Wood (2018); } \\
\text { Koutropoulos (2013); } \\
\text { Graff et al. (2013); Davis } \\
\text { \& Surajballi (2014) }\end{array}$ & $\begin{array}{l}\text { Vendors are invited to present their products to faculty, students, administrators, and } \\
\text { technical groups in on-site meetings. }\end{array}$ \\
\hline $\begin{array}{l}\text { Technical Testing } \\
\text { and Evaluation }\end{array}$ & $\begin{array}{l}\text { Graff et al. (2013); Davis } \\
\text { \& Surajballi (2014) }\end{array}$ & $\begin{array}{l}\text { After the presentation, the committee invites instructors and support staff to test the } \\
\text { proposed systems and then evaluates their feedback. }\end{array}$ \\
\hline $\begin{array}{l}\text { Decision/Solution- } \\
\text { selection }\end{array}$ & $\begin{array}{l}\text { Boggs, \& Van Baalen- } \\
\text { Wood (2018); Graff et al. } \\
(2013)\end{array}$ & Final decision about the best LMS is made based on previous testing. (Rule of $80 / 20$ ). \\
\hline \multicolumn{3}{|l|}{ Align Implementation } \\
\hline $\begin{array}{l}\text { Development of } \\
\text { Implementation, } \\
\text { Monitoring, and } \\
\text { Improvement Plan }\end{array}$ & $\begin{array}{l}\text { Davis, \& Surajballi } \\
\text { (2014); Strawser et al. } \\
(2018)\end{array}$ & $\begin{array}{l}\text { Having an implementation plan and team are vital to put in strategies to aid the } \\
\text { implementation process. }\end{array}$ \\
\hline $\begin{array}{l}\text { Communication } \\
\text { Strategies and } \\
\text { Informational } \\
\text { Sessions }\end{array}$ & $\begin{array}{l}\text { Hannon, Hirst \& Riddle } \\
\text { (2011); Ryan et al. } \\
\text { (2012); Boggs \& Van } \\
\text { Baalen-Wood (2018); } \\
\text { Butakov et al. (2013); } \\
\text { Davis \& Surajballi } \\
\text { (2014); Graff et al. } \\
\text { (2013); Koutropoulos } \\
\text { (2013); Strawser et al. } \\
\text { (2018) }\end{array}$ & $\begin{array}{l}\text { Developing and maintaining robust communication strategies is essential in keeping } \\
\text { people informed and apprised of the next steps in the transition, training, and ongoing } \\
\text { support. Multiple informational/introductory sessions can be provided across campus } \\
\text { and online for faculty, students, and staff to support the LMS implementation. }\end{array}$ \\
\hline
\end{tabular}




\begin{tabular}{|c|c|c|}
\hline $\begin{array}{l}\text { Execution of } \\
\text { Implementation Plan } \\
\text { with Necessary: } \\
\text { *Training } \\
\text { *Support } \\
\text { * Collaboration and } \\
\text { Cooperation } \\
\text { * Resources \& } \\
\text { Leadership } \\
\text { *Incentives, Rewards } \\
\text { \& Early Adopters. } \\
\text { *Taking Learning } \\
\text { Ownership } \\
\text { *Integration with } \\
\text { Other Relevant } \\
\text { Institutional } \\
\text { Structures and } \\
\text { Processes }\end{array}$ & $\begin{array}{l}\text { Boggs \& Van Baalen- } \\
\text { Wood (2018); } \\
\text { Butakov et al. (2013); } \\
\text { Killewo et al. (2014); } \\
\text { Judge \& Murray (2017); } \\
\text { Sanga (2016); } \\
\text { Hannon et al. (2011); } \\
\text { Ryan et al. (2012); } \\
\text { Strawser et al. (2018) }\end{array}$ & $\begin{array}{l}\text { Multifaceted training can be offered to users around content migration through: } \\
\text { - } \quad \text { workshops (basic and advanced skills workshop, foundational and targeted } \\
\text { - } \quad \text { sorkshops) } \\
\text { - digital training repository } \\
\text { - } \text { boot camp } \\
\text { - and on-demand training. } \\
\text { Robust support from a support team that includes the vendor, IT, and instructional } \\
\text { support personnel, that can be offered } 24 / 7 \text { through: } \\
\text { - Phone calls } \\
\text { - } \quad \text { omail, } \\
\text { - video guides } \\
\text { - PDF guides } \\
\text { - help page } \\
\text { - one-on-one-appointments } \\
\text { - Support and encouragement from leadership are crucial to empower stakeholders. } \\
\text {-Recruiting early adopters and providing incentives to pilot the system and guide the } \\
\text { migration process are vital. } \\
\text { - Integrating the new LMS with other relevant structures and processes in the } \\
\text { institution. } \\
\text {-Encouraging academics to take ownership of what they do is key. }\end{array}$ \\
\hline $\begin{array}{l}\text { Monitoring and } \\
\text { Continuous } \\
\text { Improvement }\end{array}$ & Judge \& Murray (2017) & $\begin{array}{l}\text { At the completion of the transition, continuous evaluation and feedback from faculty } \\
\text { and students through surveys will be vital to determine the effectiveness of the project } \\
\text { and to suggest plans for improvement. }\end{array}$ \\
\hline
\end{tabular}




\section{Discussion}

It is interesting to note that many of the strategies that emerged from the literature are clustered around the final phase of the LDSA framework, "implementation". Given that the stakeholder buy-in process starts much sooner, during the clarify expectations stage, it may not be surprising that, as Dobbin (2016) asserts, change management is often faced with resistance to change. Additionally, given that other early change management phases, as outlined in the LDSA framework, allow us to identify or validate priority needs based on various sources of data and analyze various options based on solution requirements that are specific to our own institutional needs and realities, it seems logical to wonder whether this could partially explain the significant failure rate (as high as 70\%) of institutional change initiatives (Al-Haddad \& Kotnour, 2015; Hornstein, 2015; Balogun \& Hailey, 2004).

When we talk about managing a change or initiative, people often think of implementing something, but the management of the change starts much earlier during the planning stage. There seems to be a disconnect between change planning and change implementation. Williams, et al. (2019) argue that the dedicated literature on the front-end of projects is sparse, though the front-end has been shown to be critical to the strategic success of projects.

Similarly, Guerra-Lopez and Hicks (2017) have previously argued that most failed implementations of organizational initiatives stem from either a disconnect in properly assessing the needs of the organization and selecting the best solution(s) for addressing those needs or from poor or non-existing strategies for purposefully integrating the solution and managing the change from a system view.

Figure 2 illustrates a contextualized strategic alignment framework to guide a systemic process for planning and managing change. The framework organizes specific change management strategies based on current published case studies. However, those strategies should be contextualized to best fit the unique situation for each institution, and further may not flow neatly in the same order as suggested. Reality, particularly in institutional settings, is complex and does not always fit perfectly into models, diagrams, and flowcharts.

\section{Conclusion}

Effectively implementing planned organizational change is one of the most significant challenges for leaders in HEIs and managing technological changes is a key concern (Ryan et al., 2012). This study sought to propose an integrated framework for helping leaders manage technological change in HEIs. One of the limitations of this study is the modest number of case studies included in the analysis. While the researchers could have increased the sample size by expanding the inclusion criteria to a wider variety of empirical articles, we wanted to maintain focus on providing HEI leaders an applied framework that reflected strategies that had been applied in similar contexts. Further research is needed to identify a broader set of strategies and their level of effectiveness when applied as part of a systematic and integrated approach. 


\section{Figure 2.}

A Synthesis of Technological Change Management Strategies in Higher Education by Strategic Alignment for Learning and Development Phases (Adapted from Guerra-Lopez \& Hicks's framework, 2017).

Align Expectations: Understand what stakeholders want

- Engage stakeholders

- Clarify stakehold erexpectations

- Identify change agents

Align Results: Translate stakehlder wants into results; Identfiy critical gaps

- Identfiy gaps and needs

- Conduct institutianl (resources) analysis

Align Solutions: Analize gaps for solution selection; Align solutions to gaps

- Conduct participatory solution analysis

- Locate experiences of peer institutions

- Review requests for proposals

- Facilitate vendor presentations and review

- Conduct technical testing and evaluation

- Decision/solution selection

Align Implementation: Design alignment strategies

- Develop implementation, monitoring, and improvement plan

- Define communication strategies and facilitate information sessions

- Execute implementation plan with necessary support (e.g. training, collaboration, leadership, tools/resources, incentives and rewards, institutional structures and processes, etc)

-Develop and execute monitoring, change management, and continuous improvement plan 


\section{References}

Adams Becker, S., Cummins, M., Davis, A., Freeman, A., Hall Giesinger, C., \& Ananthanarayanan, V. (2017). NMC horizon report: 2017 higher education edition. Austin, Texas: The New Media Consortium.

Al-Haddad, S., \& Kotnour, T. (2015). Integrating the organizational change literature: A model for successful change. Journal of Organizational Change Management, 28(2), 234-262.

Bates, AW. T. (2019). Teaching in a digital age: Guidelines for designing teaching and learning (2nd ed.). Tony Bates Associates Ltd. https://pressbooks.bccampus.ca/teachinginadigitalagev2/

Bates, A. W. (2000). Managing technological change: Strategies for college and university leaders. Jossey-Bass Publishers.

Boggs, C., \& Van Baalen-Wood, M. (2018). Diffusing change: Implementing a university-wide learning management system transition at a public university. In Leading and Managing $e$ Learning (pp. 115-128). Springer.

Balogun, J., \& Hailey, H. V. (2004). Exploring strategic change. Prentice Hall.

Butakov, S., Solodky, O., \& Swar, B. (2013). LMS implementation in startup institutions: Case study of three projects. In Yefim Kats (Ed), Learning Management Systems and Instructional Design: Best Practices in Online Education (pp. 40-54). IGI Global.

Dahlstrom, E. D., Brooks, C., \& Bichsel, J. (2014). The Current ecosystem of learning management systems in higher education: Student, faculty, and IT perspectives. Research report. Louisville. https//dx.doi.org/10.13140/RG.2.1.3751.6005

Davis, R., \& Surajballi, V. (2014). Successful implementation and use of a learning management system. The Journal of Continuing Education in Nursing, 45(9), 379-381.

Finn III, E. (2017). Faculty perceptions of the transition of a learning management system through the lens of organizational change: A case study. Indiana Wesleyan University.

Graff, R., Johnson, D., \& Means, T., (2013). Lessons learned from a course management system review at the University of Florida. In Yefim Kats (Ed), Learning Management Systems and Instructional Design: Best Practices in Online Education (pp. 55-71). IGI Global.

Guerra-López, I. (2018). Ensuring measurable strategic alignment to external clients and society. Performance Improvement, 57(6), 33-40.

Guerra-López, I., \& Hicks, K. (2017). Partner for performance: Strategically aligning learning and development. Association for Talent Development. 
Hannon, J., Hirst, D., \& Riddle, M. (2011). Implementing e-learning: A migration story. In G. Williams, P. Statham, N. Brown, \& B. Cleland (Eds.), Changing demands, changing directions: Proceedings of the ASCILITE 2011 Conference (pp. 557-561). Retrieved from: http://www.ascilite.org/conferences/hobart11/downloads/papers/Hannon-concise.pdf

Hicks, K. (2015). Construct validation of a learning \& talent development strategic alignment scale. (Publication No. 3700629). Doctoral Dissertation, Wayne State University. ProQuest Dissertations Publishing.

Hornstein, H. A. (2015). The integration of project management and organizational change management is now a necessity. International Journal of Project Management, 33(2), 291-298.

Hsieh, H.-F., \& Shannon, S. E. (2005). Three approaches to qualitative content Analysis. Qualitative Health Research, 15(9), 1277-

1288. https://doi.org/10.1177/1049732305276687

Judge, D. S., \& Murray, B. (2017). Student and faculty transition to a new online learning management system. Teaching and Learning in Nursing, 12(4), 277-280.

Jin, Y., Hopkins, M. M., \& Wittmer, J. L. S. (2010). Linking human capital to competitive advantages: Flexibility in a manufacturing firm's supply chain. Human Resource Management, 49(5), 939-963.

Kaufman, R. (2019). Alignment and success: Applying the hierarchy of planning and the needsassessment hierarchy. Performance Improvement, 58(7), 24-28.

Killewo, L., Lisasi, E., Kapanda, G., Tibyampansha, D., Ibrahim, G., Kulanga, A., \& Kessi, E. (2014). Introduction of a learning management system at the Kilimanjaro Christian Medical University College. African Journal of Health Professions Education, 6(1), 37-40.

Koutropoulos, A. (2013). Learning management system evaluation and selection: A case study of the University of Massachusetts system methodology for the learning platform Review. In Learning Management Systems and Instructional Design: Best Practices in Online Education (pp. 20-39). IGI Global.

Pahl, C. (2003). Managing evolution and change in web-based teaching and learning environments. Computers \& Education, 40(2), 99-114.

Piña, A. A. (2018). An educational leader's view of learning management systems. In Piña, A., Lowell, V., Harris, R. (Eds), Leading and Managing e-Learning (pp. 101-113). Springer. IGI Global.

Ryan, T. G., Toye, M., Charron, K., \& Park, G. (2012). Learning management system migration: An analysis of stakeholder perspectives. The International Review of Research in Open and Distributed Learning, 13(1), 220-237. 
Sanga, M. W. (2016). An analysis of technological issues emanating from faculty transition to a new learning management system. Quarterly Review of Distance Education, 17(1), 11-21.

Schein, E.H. (1985). Organizational Culture and Leadership: A Dynamic View. Jossey-Bass: San Francisco, CA.

Schein, E. H., \& Schein, P. A. (2016). Organizational Culture and Leadership, 5th Edition. Wiley.

Smart, K. A., \& Meyer, K. A. (2005). Changing course management systems: Lessons learned. Educause Quarterly, 28(2), 68-70.

Strawser, M. G., Apostel, S., O'Keeffe, M., \& Simons, C. (2018). Implementing innovation: An exploration of a learning management system transition. The Journal of Faculty Development, 32(2), 37-43.

Such, B. L., Ritzhaupt, A. D., \& Thompson, G. S. (2017). Migrating learning management systems: A case of a large public university. Administrative Issues Journal, 7(2), 6.

Tabrizi, B., Lam, E., Girard, K. \& Irvin, V. (2019). Digital transformation is not about technology. Business Review. https://hbr.org/2019/03/digital-transformation-is-not-abouttechnology

Walter, J., Kellermanns, F. W., Floyd, S. W., Veiga, J. F., \& Matherne, C. (2013). Strategic alignment: A missing link in the relationship between strategic consensus and organizational performance. Strategic Organization, 11(3), 304-328.

Williams, T., Vo, H., Samset, K., \& Edkins, A. (2019). The front-end of projects: a systematic literature review and structuring. Production Planning \& Control, 30(14), 1137-1169.

Wilson, B.G. (1999). Evolution of learning technologies. From instructional design to performance support to network systems. Educational Technology, 39(2), 32-35. 